\title{
Study the Influence of Doping Electric and Magnetic Nanoparticles on the Nonlinear Optical Properties of Nematic Liquid Crystals
}

\author{
Aseel Mahmood ${ }^{1}$, Rawa Ibrahim ${ }^{1}$, Ali Abdullah ${ }^{2}$, Ali Baki ${ }^{1}$, Ghaidaa Khudair ${ }^{1}$, \\ Veronika Gdovinova ${ }^{3}$, Peter Kopcansky ${ }^{3}$ \\ ${ }^{1}$ Materials Research Directorate, Ministry of Science and Technology, Baghdad, Iraq \\ ${ }^{2}$ Iraqi Civil Aviation Authority, Baghdad, Iraq \\ ${ }^{3}$ Institute of Experimental Physics SAS, Watsonova 47, 04001 Košice, Slovakia \\ Corresponding author: Aseelibrahim208@gmail.com
}

\begin{abstract}
Key words

In this work, the nonlinear optical properties response of nematic liquid crystal (6CHBT) and the impact of doping with two kinds of nanoparticles; $\mathrm{Fe}_{3} \mathrm{O}_{4}$ magnetic nanoparticles and $\mathrm{SbSI}$ ferroelectric nanoparticles have been studied using the non-linear dynamic method through z-scan measurement technique. This was achieved utilizing $\mathrm{CW} \mathrm{He}-\mathrm{Ne}$ laser. The pure LC and magnetic LC Nematic LC, Z-Scan technique, ferronematic $L C$ composite, ferroelectric $L C$ composite. nanoparticle composite samples had a maximum absorption while the ferroelectric LC nanoparticle composite had a minimum absorption of the incident light. The nonlinear refractive index was positive for the pure and the doped magnetic nanoparticles LC composite samples, while it was negative for the doped ferroelectric LC composite. Studying the nonlinear optical properties of these types of

Article info.

Received: Aug. 2020

Accepted: Sep. 2020 liquids is very helpful in the field of liquid crystal applications like display screen and spatial light modulators.

$$
\begin{aligned}
& \text { دراسة تاثير التطعيم بالجزيئات النانوية الكهربائية والمغناطيسية على الخواص البصرية } \\
& \text { اللاخطية للبلورات السائلة النيماتية }
\end{aligned}
$$

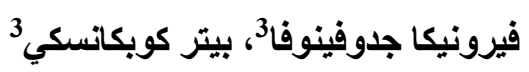

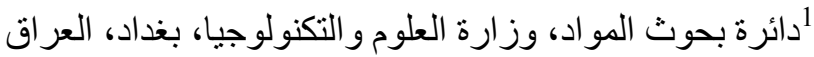

$$
\begin{aligned}
& \text { 2لطة الطير ان المدني، بغداد، العراق }
\end{aligned}
$$

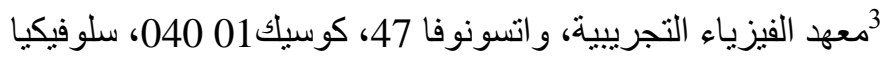$$
\text { اسيل ابراهيم محمود1، روى خليل ابراهيم، علي عزام عبد الله²، علي قادر بكي1، غيداء حمزة خضير1، }
$$

Published: Dec. 2020

الخلاصة

في هذا العمل نم دراسة استجابة الخصائص البصرية اللاخطية للسائل النيماتي 6CHBT ودراسة تأنأثير

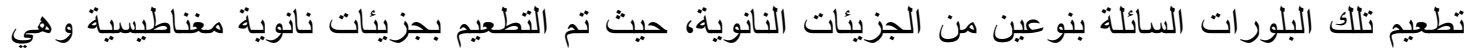

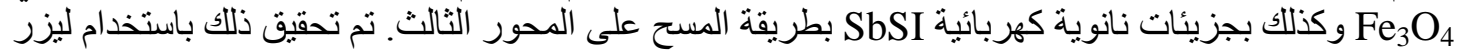

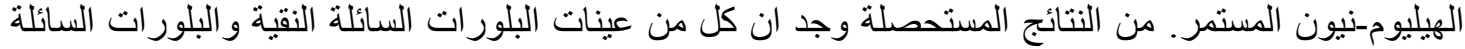

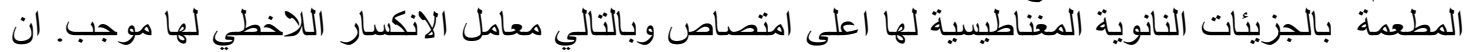

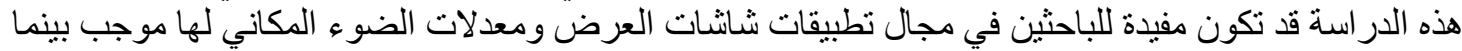

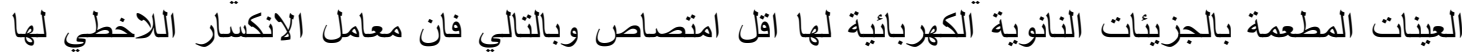

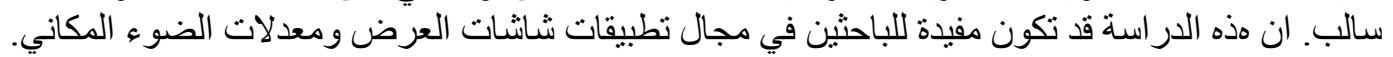




\section{Introduction}

Liquid Crystals (LC's) are considered to be very important material. This is due to their unique physical, optical and electro-optical properties. Most of nematic LC's devices were driven by electric fields. Because of the strong correlation among the LC molecules arrangement line due to the high anisotropy of diamagnetic susceptibility. Also, the dielectric permittivity anisotropy of LCs is relatively large. Thus few volts are enough to control the orientation response of the LC's molecules [1]. Due to the above, LC's have huge applications in different fields like biomedicine, E-books, optical light valves, microwave technology, and many others [2].

Doping LC's with Nanoparticles (NP's) became a very important topic in the field of enhancing the performance and the application of LCs.This topic had been developed due to the growth of nanotechnology in the late 1990s. Brochard and P. G. de Gennes in 1970 were the first scientists who submitted this idea. They also predicted that doping of ferromagnetic particles to the LCs increases the response of the medium to the magnetic fields due to maximizing the anisotropic diamagnetic susceptibility value $(\Delta \chi)$. Different NP's were used to be mixed with LC's including magnetic, ferroelectric, dielectric, semiconductor, metal, polymer, and carbon-based (nanotubes, fullerenes, etc.) [3].

The ferronematic material concept belongs to the mixture of LC's and NP's. The materials in the mixture can be fully controlled by a rather weak magnetic field (much less than $10 \mathrm{mT}$ ) [4]. When stimuli were applied to ferronematic materials the rotation influence will affect the host nematic due to the coupling between the NP's and LC's molecules. The realignment of the host nematic molecules dipoles is developed by the NP's properties.

In other words, it is not influenced by LC's intrinsic diamagnetic properties due to strong anchoring of $\mathrm{n} \| \mathrm{m}$, the unit vector of the preferred direction of the nematic molecules (director) represent by $n$, and $m$ is the unit vector of the magnetic moment of the magnetic particles [5].

Doping LC's with magnetic NP's essentially depend on their size, shape, and structure. Controlling these parameters is considered an ultimate challenge in material science. When LC's doped with NP's, these particles act as single magnets and exhibit unusual properties called super-Para magnetism [6]. The doping NP's shape, size type, and concentrations represent the most effective parameters which lead to the modification and enhancement of the electro-optical properties of LC's [7].

Many types of ferronematics suspension using different thermotropic liquid crystal matrices were introduced by Kopcansky and others. $\mathrm{Fe}_{3} \mathrm{O}_{4}$ of diameter $\sim 10 \mathrm{~nm}$, coated with oleic acid, volume concentration 10-3 to 10-5 in ZLI 1695 and 6CHBT; also $\mathrm{Fe}_{3} \mathrm{O}_{4}$ needle-like covered with surfactant in 5CB; FeCo in $8 \mathrm{CB}$ were submitted. $\mathrm{Fe} 3 \mathrm{O} 4$ of different shapes (spherical- $12 \mathrm{~nm}$, rod-like- $80 \mathrm{~nm}$, chain-like $500 \mathrm{~nm}$ ) in 6CHBT and functionalized CNTs with the magnetic particle of $\mathrm{Fe}_{3} \mathrm{O}_{4}$ were also studied in 6CHBT $[8,9]$.

Doping LC's with electric NP's (which are called ferroelectric LC's) have received a lot of attention due to their amazing properties and important applications in many fields such as optical antennas, spatial light modulators for optical storage, flat panels and switching displays. The Ferroelectric LC's are characterized by their fast response time, low threshold voltage, better contrast ratio, wide viewing angle and memory. The ferroelectric LC's were fabricated through mixing ferroelectric nanomaterials of small percentage with the host LC $[10,11]$.

Ferroelectric LC had been presented by many researchers, Kurochkin et al. [12] exhibit different behaviours of 5CB- LC doped with ferroelectric NP's 
( $\mathrm{SPS}=\mathrm{Sn}_{2} \mathrm{P}_{2} \mathrm{~S}_{6}$ ). These behaviours affect the threshold voltage by increasing and decreasing it and the "nematic-isotropic" phase transition temperature. Patricio et al. [13] studied the possibility of using a nanocomposite consisting of a ferroelectric LC and a magnetic NP as a magnetic resonance imaging contrast agent. They used 2-(4((2-fluorooctyl)oxy)phenyl)-5-(octyloxy)pyrimidine ferroelectric LC doped with FeCo NPs of diameter 2-3 nm. Marzal et al. [14] analysed the electrical behaviour of a titanium dioxide (TiO2) NP-LC doped cell. The presence of NP's lead to increase in the temperature sensitivity of the equivalent cell capacitance and the capacitance difference between switched and non- switched states. The submitted design would be very useful in the field of LC electronic devices and sensors.

Hammudi et al. [15] measured the non-linear refractive index (NLR) and nonlinear absorption (NLA) of water-based ferrofluids of different diameters of NP's 5, and $10 \mathrm{~nm}$. Each sample had a positive NLR. Also, Hammudi et al. [16] studied the response of 6CHBT- LC doped with magnetic and electric NP's to the applied electric field. They found that the ferroelectric LC was more responsive to the applied electric field due to the nature of the constituent material. Abdullah et al. [17] improved the non -linear optical properties of nematic LC by doping it with gold NP's. They found that due to doping the behaviour of pure LC was changed from two photon absorption to saturable absorption.

In this work, the non-linear optical properties were investigated through the z-scan technique. The nonlinear refractive index and non- linear absorption were measured for pure LC, and LC doped with magnetic NP's and electric NP's.

\section{Experimental work}

The single beam measurements through the Z-scan technique had been proposed in 1989 by Sheik-Bahae et al. [18]. Through this method, the NLR and NLA will be calculated. This technique is a simple method that depends on measuring the intensity-dependent nonlinear susceptibilities of materials under investigation. Fig.1 shows the schematic diagram of the Z-scan measurement technique.

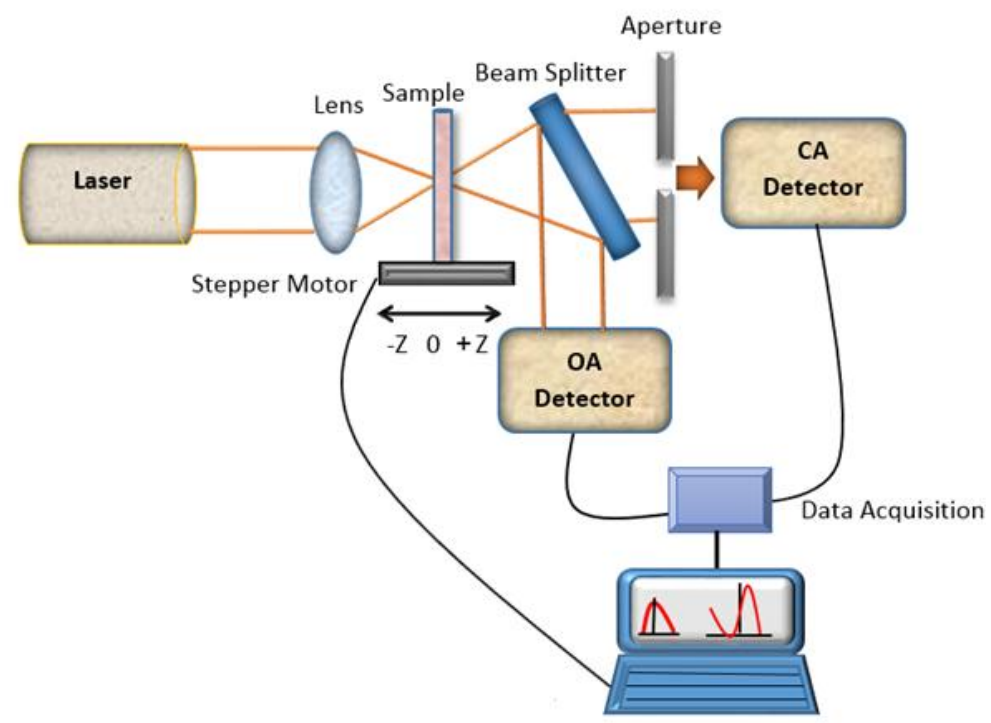

Fig.1: Schematic diagram of the single beam measurement experimental setup.

At the closed aperture (CA) side of the detector, the relative transmittance of the sample under testing is given by [18]: 


$$
T\left(Z, \Delta \phi_{0}\right)=1-\frac{4 \Delta \phi_{0} \frac{Z}{Z_{0}}}{\left[\left(\frac{Z^{2}}{Z_{0}^{2}}\right)+9\right]\left[\frac{Z^{2}}{Z_{0}^{2}+1}\right]}
$$

$\mathrm{T}$ is defined as is the transmission of laser light through the aperture. This value is a function of the sample position $\mathrm{Z}$. and $\mathrm{Z}_{0}$ is the Rayleigh wavelength and $\Delta \Phi_{\mathrm{o}}$ is the on-axis phase shift at the focus zone, and it could be found according to Eq.(2) below [18]:

$$
\Delta T_{p-v} \approx 0.406(1-S)^{0.25} \Delta \phi \text { 。 }
$$

$\Delta T_{p-v}$ is measured by measuring the difference between the normalized peak and valley transmittance. $\mathrm{S}$ is linear transmittance of the aperture [18]:

$$
S=1-\exp \left(-2 r_{a}^{2} / w_{a}^{2}\right)
$$

Where $r_{a}$ represents the aperture radius and $w^{a}$ is the beam radius at the aperture. The NLR $\left(\mathrm{n}_{2}\right)$ could be found through the following equation [18]:

$$
n_{2}=\frac{\Delta \phi_{0}}{I_{0} L_{e f f} k}
$$

Where: $\mathrm{k}=2 \pi / \lambda, \lambda$ is the laser wavelength, $\mathrm{I}_{\mathrm{o}}$ is the maximum intensity within the sample cell at the focus and the $\mathrm{L}_{\text {eff }}$ is the effective thickness, which is given by [18]:

$$
L_{e f f}=\left[1-\exp \left(-\alpha_{0} L\right)\right] / \alpha_{0}
$$

where $\alpha_{0}$ is the linear absorption coefficient of the samples and it is obtained through Beer-Lambert law that defines based on $\alpha=-\left(\frac{1}{l}\right) \ln \ln I / I_{0}$ in the linear regime of the experiment. While the NLA $(\gamma)$ was calculated according to [18]:

$$
\gamma=\frac{2 \sqrt{2} \Delta T}{I_{0} L_{e f f}}
$$

The 6CHBT- LC (thermotropic nematic 4-(trans-4'-n-hexylcyclohexyl)(isothiocyanatobenzene) had been used in this work. The 6CHBT is considered as a low-temperature-melting enantiotropic LC. This type of LC has high chemical stability. The phase transition temperature from the isotropic liquid to the nematic phase is $42.6{ }^{\circ} \mathrm{C}$ [19], the chemical structure of the submitted LC is presented in Fig.2.
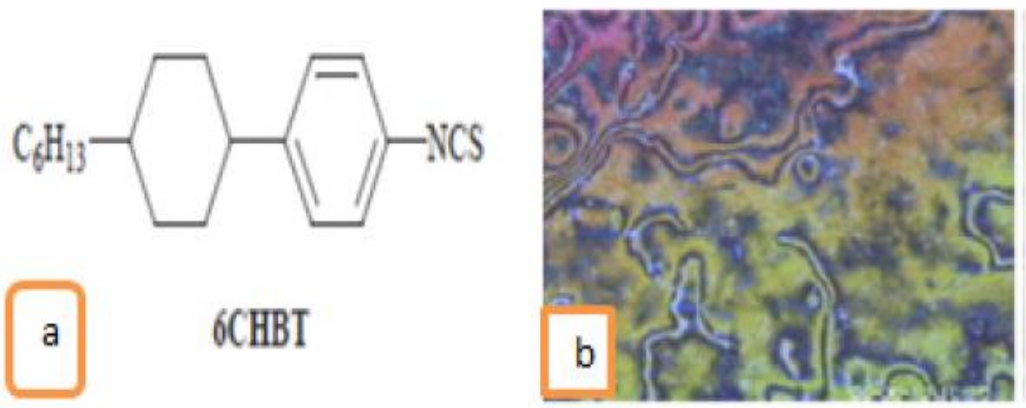

Fig.2: a Chemical structure of 6CHBT LC, b: 6CHBT LC image under the microscope [16].

6CHBT had been doped (in the isotropic phase under continuous stirring) with different NP's. A magnetic suspension consisting of rod-like $\mathrm{Fe}_{3} \mathrm{O}_{4}$ NP's coated with Oleic acid as a surfactant was used. The average diameter of rod-like NP's was $16 \mathrm{~nm}$ and the mean length determined from the histogram of the size distribution was 70 $\mathrm{nm}$. The morphology and size distribution of the doped NP's were studied by transmission electron microscopy (TEM) (Tesla BS 500) as shown in Fig.3. 


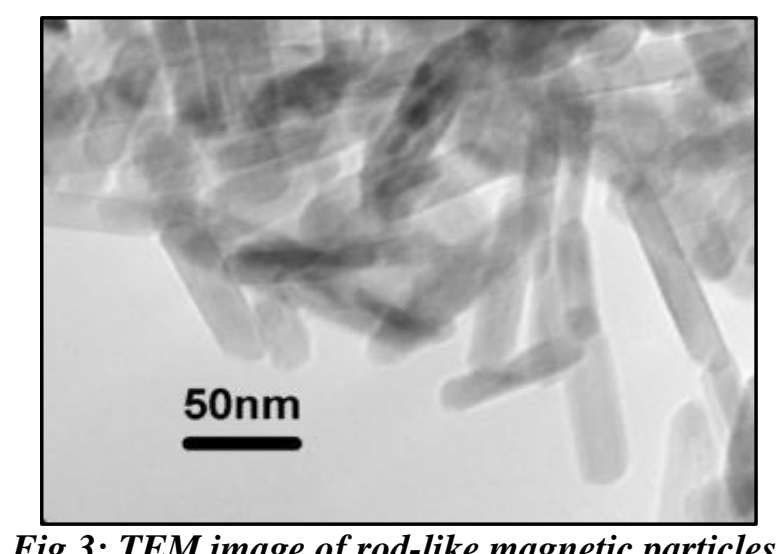

Fig.3: TEM image of rod-like magnetic particles.

The ferroelectric SbSI NP's were used for doping 6CHBT-LC. These NP's were spherical shape with grain size of $88 \mathrm{~nm}$. The ferroelectric, as well as the ferromagnetic nanoparticles, were of a mono-domain type and oleic acid was used as a surfactant to avoid aggregation. These suspensions were added to LC under continuous string, the volume concentration $(\phi)$ of 6CHBT was $\left(\phi=2 \times 10^{-3}\right)$.

The sample cell is composed of two glass slides which were coated with polyvinyl alcohol (PVA) by the spin coating technique. The separation between these two slides is $20 \mu \mathrm{m}$ done by a thin film of the mask with a square shape. The sample liquids were injected in this square mask. Lastly, the sample cell was sealed with an adhesive material to inventory the Ferro-materials. The sample cells then will be located in the sample chamber in the z-scan setup.

The experimental setup shown in Fig.1 was used to measure the nonlinear refractive index and absorption of pure LC, ferronematic and ferroelectric LC composite. A CW He: Ne laser operating at $632.8 \mathrm{~nm}$ was used as the light source. A converging lens of focal length about $10 \mathrm{~cm}$ had been used to focus the laser light onto the samples under test. The manufactured samples had a thickness of $2 \mathrm{~mm}$. These samples were mounted on a moving motorized stage around the focus area. This movement is controlled by a computer with a step of $10 \mu \mathrm{m}$. The transmission intensity as a function of position was collected from each optical detector OA (Open Aperture) and CA (Closed Aperture), the diameter of aperture was $1 \mathrm{~mm}$. These data had been processed through specially designed software. Eq.4 was applied with the data collected from the CA experiments to measure the NLR, while OA data were used to calculate the NLA through Eq.(6).

\section{Results and discussion}

As the ferronematic LC composite, ferroelectric LC composite samples were transferred through the focal region of the He-Ne laser beam, the OA detector measures the total transmission intensity of the laser as clear in figure 4. One can notice from the obtained figure that $\mathrm{Z}$-scan traces for all samples are symmetric around the focal point $(\mathrm{z}=0)$. They have a maximum for the saturation absorption for pure LC and rod-like ferronematic LC composite as is clear in Fig.4 (a) and (b). While exhibiting a minimum transmittance in the case of measuring the nonlinear absorption (multiphoton absorption) for ferroelectric LC composite, shown in Fig.4(c). Table 1 shows the results of nonlinear absorption of the previous samples which were calculated according to Eq.(6). 

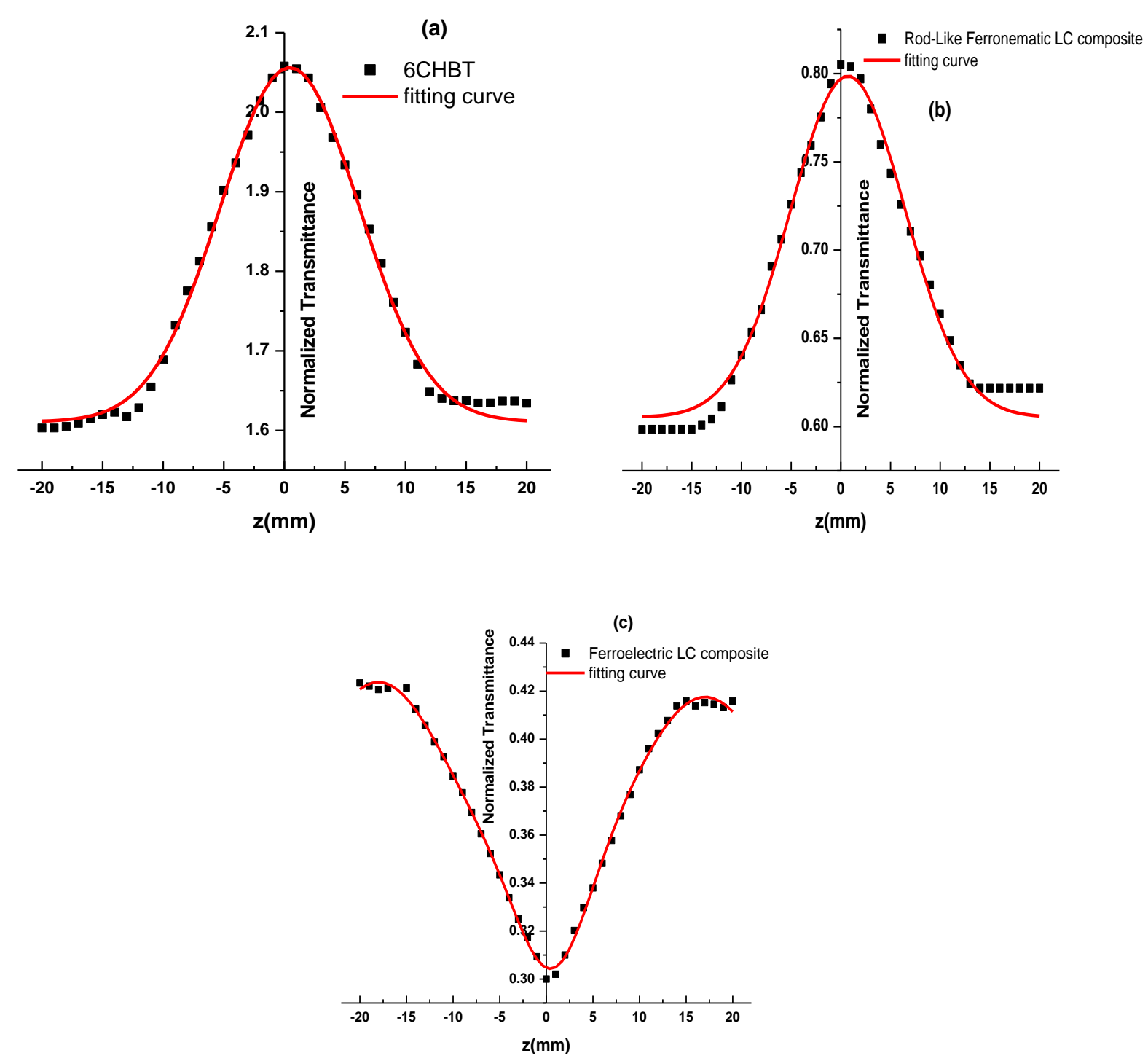

Fig.4: The nonlinear absorption coefficient, (a) pure 6CHBT, (b) Rod-like Ferronematic LC composite, and (c) Ferroelectric LC composite.

Table 1: The nonlinear absorption of the three samples.

\begin{tabular}{|c|c|c|c|}
\hline Sample & 6CHBT & $\begin{array}{c}\text { Rod-like } \\
\text { Ferronematic LC } \\
\text { composite, }\end{array}$ & $\begin{array}{c}\text { Ferroelectric LC } \\
\text { composite }\end{array}$ \\
\hline$\gamma(\mathrm{cm} / \mathrm{mW})$ & 2.723 & 3.113 & 0.0051 \\
\hline
\end{tabular}

To find the NLR, the prepared samples were moved through the focal zone of the laser beam. The CA optical photo-detector measured the transmission intensity passing through the aperture or window. Then this concentrated beam is transmitted towards the sample under investigation. If the transmitted laser light suffered any nonlinear phase shift because of sample movements through the focal region, $Z=0$, this part of the transmitted light reaching the CA detector will be different due to the Kerr lens generated in the prepared samples by the focused laser beam. The position of the peak and valley in Fig.5, relative to the Z-axis, depends on the sign of the 
nonlinear phase shift, $\Delta \Phi_{\mathrm{o}}$. For the samples of pure LC and rod-like ferronematic LC composite the self-focusing phenomena occur when one gets a positive phase shift, i.e. the peak will trail the valley as it clears in Fig. 5(a) and (b). While, if the valley will trail the peak we will get a negative phase shift (i.e. self-defocusing phenomena) which was obtained for the ferroelectric LC composite, as clear in Fig. 5(c). The phase shift can be determined from the change in normalized transmittance between peak and valley, Eq. (2). The nonlinear index, $\mathrm{n}_{2}$, can then be found according to phase shift sign using, Eq. (4). Table 2 illustrates the calculated values of the nonlinear refractive index of the submitted samples.
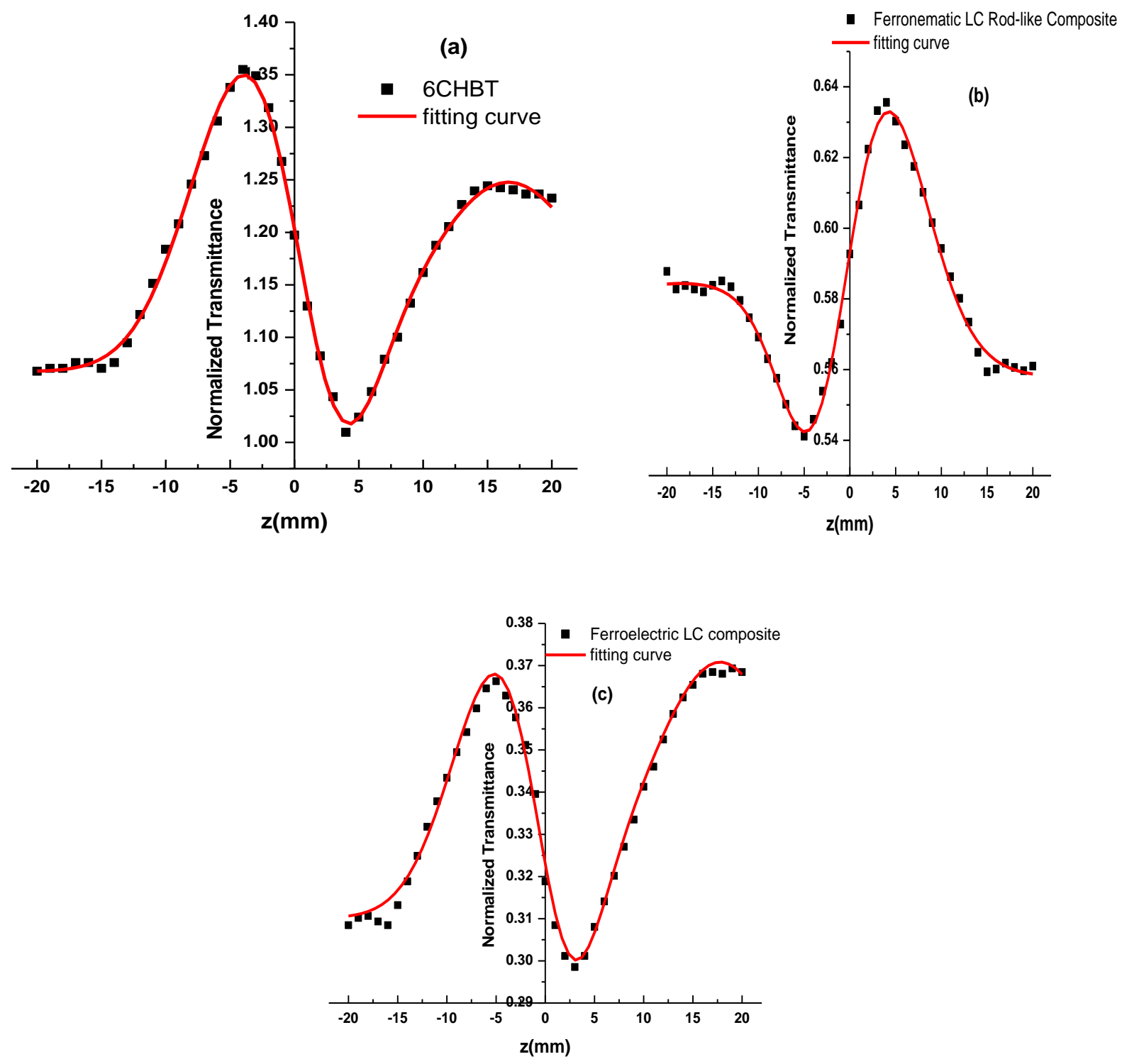

Fig.5: The nonlinear refractive index, (a) 6CHBT, (b) Rod-like Ferronematic LC composite, and (c) Ferroelectric LC composite.

Table 2: The nonlinear refractive index of the samples under investigation.

\begin{tabular}{|c|c|c|c|}
\hline Sample & 6CHBT & $\begin{array}{c}\text { Rod-like } \\
\text { Ferronematic LC } \\
\text { composite, }\end{array}$ & $\begin{array}{c}\text { Ferroelectric LC } \\
\text { composite }\end{array}$ \\
\hline$n_{2}\left(\mathrm{~cm}^{2} / \mathrm{mW}\right)$ & $2.938 \times 10^{-6}$ & $9.257 \times 10^{-7}$ & $(-) 6.081 \times 10^{-7}$ \\
\hline
\end{tabular}


The collected data of CA scan divided by the OA data determine the nonlinear phase shift which is important to find the NLR in the absence of nonlinear absorption. Fig. 6 shows the determined results, and Table 3 illustrates the calculated values.
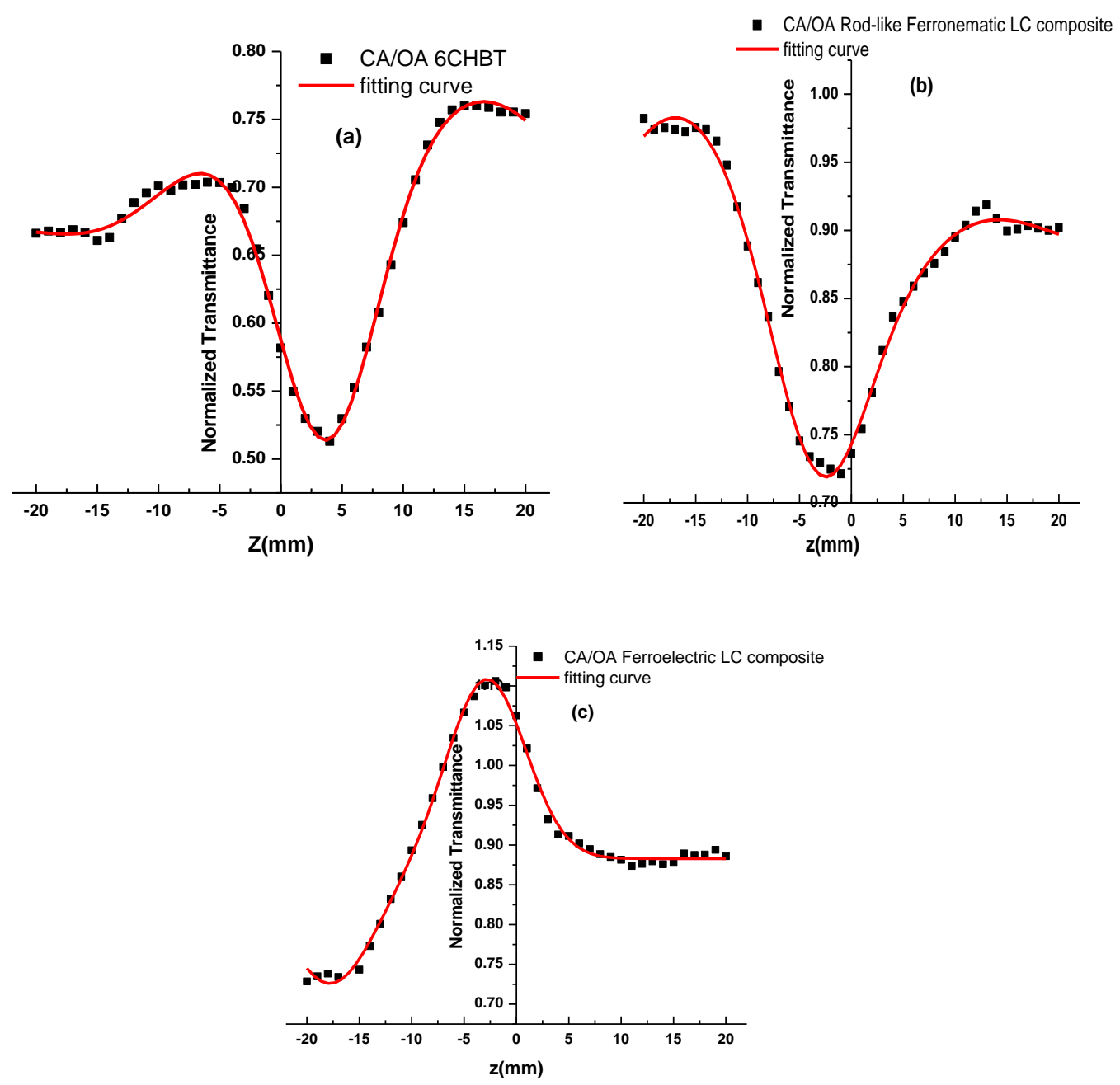

Fig.6: The nonlinear refractive index (CA/OA) case, (a) 6CHBT, (b) Rod-like Ferronematic LC composite, and (c) Ferroelectric LC composite.

Table 3: The nonlinear refractive index of the submitted samples in case of division CA over $\mathrm{OA}$.

\begin{tabular}{|c|c|c|c|}
\hline Sample & 6CHBT & $\begin{array}{c}\text { Rod-like } \\
\text { Ferronematic LC } \\
\text { composite, }\end{array}$ & $\begin{array}{c}\text { Ferroelectric LC } \\
\text { composite }\end{array}$ \\
\hline$n_{2}\left(\mathrm{~cm}^{2} / \mathrm{mW}\right)$ & $1.679 \times 10^{-5}$ & $2.433 \times 10^{-6}$ & $(-) 8.152 \times 10^{-6}$ \\
\hline
\end{tabular}

\section{Conclusions}

In this work, the influence of doping nematic LC with magnetic and electric nanoparticles was studied. In the case of nonlinear absorption, the pure LC and rodlike ferronematic composite exhibit maximum saturation absorption, while exhibiting a minimum transmittance (multiphoton absorption) for ferroelectric LC composite. The nonlinear refractive index was positive for the pure LC and rod-like ferronematic 
LC composite due to self-focusing phenomena, while it was negative for ferroelectric LC composite due to self-defocusing phenomena. These results could be very useful in the application of LC's in magnetic and electric switching.

\section{Acknowledgements}

This work was supported by the Slovak Research and Development Agency under the contracts Nos. 015-0453, by the Ministry of Education Agency for Structural Funds of EU (Project ITMS 26220220012 and 26220220186) by the Slovak Scientific Grant Agency project VEGA 2/0016/17.

\section{References}

[1] M. Munna, F. Anwar, R. Coutu, Technologies. 7, 32 (2019) 1-28.

[2] P. Yaghmaee, O.H. Karabey, B. Bates, C. Fumeaux, R. Jakoby, Int. J. Antennas Propag, 2013 (2013) 1-9.

[3] J.B. Poursamad, M. Emdadi, Acta Phys. Pol. A., 136 (2019) 861-865.

[4] P. Kopčanský, N. Tomašovičová, M. Konerackă, V. Závišová, M. Timko, M. Hnatič, N. Éber, T. Tǒth-Katona, J. Jadzyn, J. Honkonen, E. Beaugnon, X. Chaud, IEEE Trans. Magn., 47 (2011) 4409-4412.

[5] S.T. Riahinasab, A. Keshavarz, C.N. Melton, A. Elbaradei, G.I. Warren, R.L.B. Selinger, B.J. Stokes, L.S. Hirst, Nat. Commun., 10 (2019) 1-10.

[6] A. Akbarzadeh, M. Samiei, S. Davaran, Nanoscale Res. Lett. 7, 144 (2012) 1-13.

[7] F. Galvan, V. Barranco, J.C. Galvan, S. Batlle, S. Fajardo, Intech Open, the world ' s leading publisher of Open Access books Built by scientists, for scientists TOP $1 \%$, Intech. i (2016) 13.

[8] P. Kopuanský, N. Tomąvicová, V. Gdovinová, M. Timko, N. Éber, T. TóthKatona, J. Jadzyn, J. Honkonen, X. Chaud, Acta Phys. Pol. A., 127 (2015) 157-162.

[9] K. Csach, A. Juríková, J. Miškuf, N. Tomašovicová, V. Gdovinová, V. Závišová, P. Kopcanský, N. Éber, K. Fodor-Csorba, A. Vajda, Acta Phys. Pol. A., 131 (2017) 949-951.

[10] J.P.F. Lagerwall, G. Scalia, Curr. Appl. Phys., 12 (2012) 1387-1412.

[11] Y. Garbovskiy, A. Glushchenko, Nanomaterials. 7, 361 (2017) 1-20.

[12] O. Kurochkin, H. Atkuri, O. Buchnev, A. Glushchenko, O. Grabar, R. Karapinar, V. Reshetnyak, J. West, Y. Reznikov, Condens. Matter Phys., 13 (2010) 1-9.

[13] P.N. Romero-Hasler, L.K. Kurihara, L.O. Mair, I.N. Weinberg, E.A. SotoBustamante, L.J. Martínez-Miranda, Liq. Cryst., 47 (2020) 169-178.

[14] V. Marzal, M. Caño-García, J.C. Torres, X. Quintana, I. Pérez, B. GarciaCamara, J. Nanomater., 2020 (2020) 1-7.

[15] R.N. Hammudi, S.S. Al-Bassam, A.I. Mahmood, R.K. Ibrahim, P. Kopčanský, J. Nano Res., 54 (2018) 15-21.

[16] R.N. Hammudi, S.S. Al-Bassam, R.K. Ibrahim, A.I. Mahmood, P. Kopčanský, V. Gdovinova, Nano Hybrids Compos., 23 (2018) 1-7.

[17] L. Abdullah, A. Rashad, N. Jber, A. Mahmood, R. Ibrahim, Journal of Southwest Jiaotong University, 45, 5 (2019) 1-7.

[18] M. Sheik-Bahae, A.A. Said, T.H. Wei, D.J. Hagan, E.W. Van Stryland, IEEE J. Quantum Electron., 26 (1990) 760-769.

[19] J. Majorošová, N. Tomašovičová, M. Timko, M. Koneracká, I.P. Studenyak, O. V. Kovalchuk, S.O. Kovalchuk, J. Jadżyn, P. Kopčanský, Acta Phys. Pol. A., 126 (2014) 260-261 . 